\title{
Bilateral Lung transplantation for Pulmonary Artery Aneurysm with Severe Pulmonary Hypertension: An Evolution or A Revolution?
}

Samuel Jacob ${ }^{1}$, Anthony Pham ${ }^{1}$, Basar Sareyyupoglu², and Si Pham ${ }^{3}$

${ }^{1}$ Mayo Clinic

${ }^{2}$ Mayo Clinic Florida

${ }^{3}$ Mayo Clinic's Campus in Florida

May 10, 2021

\begin{abstract}
The surgical treatment of pulmonary hypertension $(\mathrm{PH})$, with or without pulmonary artery aneurysm, has evolved during the last 40 years from heart-lung transplants to bilateral lung transplants as the treatment of choice for $\mathrm{PH}$ patients with preserved
\end{abstract} right and left ventricular function and without complex cardiac abnomalies.

Bilateral Lung transplantation for Pulmonary Artery Aneurysm with Severe Pulmonary Hypertension: An Evolution or A Revolution?

Samuel Jacob, MD ${ }^{1}$, Anthony N. Pham, MS ${ }^{1}$, Basar Sareyyupoglu, MD ${ }^{1}$, Si M. Pham MD ${ }^{1}$

${ }^{1}$ Department of Cardiothoracic Surgery, Mayo Clinic, Jacksonville, Florida, USA

Short Running Title: Lung transplant in pulmonary arterial aneurysm

Corresponding Author:

Si Pham, MD, FACS

Department of Cardiothoracic Surgery,

Mayo Clinic Hospital

4500 San Pablo Rd.| Jacksonville, FL 32224.

Phone: 904-956-3212. Fax :904-956-8060 Email: Pham.Si@mayo.edu

Word Count: 1500 (without references)

Conflict of Interests : None

Funding sources: None

Disclosure: None

Abstract.

The surgical treatment of pulmonary hypertension $(\mathrm{PH})$, with or without pulmonary artery aneurysm, has evolved during the last 40 years from heart-lung transplants to bilateral lung transplants as the treatment 
of choice for $\mathrm{PH}$ patients with preserved right and left ventricular function and without complex cardiac abnomalies.

Pulmonary artery aneurysm (PAA) is a rare finding in general population, first reported at Mayo Clinic by Deterling and Clagett in postmortem of 109,571 autopsies, only 8 cases were found with incidence being $0.007 \% .{ }^{1}$ The majority of PAA cases $(80 \%)$ occur in the main pulmonary artery (PA), the rest beyond bifurcation with aneurysms involving the left PA were more common than those of the right PA. ${ }^{2}$ The definition of main PAA is still debatable. Kreibich et al., suggested that a main PA with a diameter above 29 millimeters $(\mathrm{mm})$ was considered aneurysmal. ${ }^{3}$ However, Brown et al., suggested that PAA was defined as having a main PA diameter exceeds $40 \mathrm{~mm} .{ }^{4}$ Multiple etiologies of PAA have been described, such as congenital, acquired, and idiopathic etiologies. The most common congenital anomalies are persistent ductus arteriosus, ventricular septal and atrial septal defects. ${ }^{5,6}$ There is a wide range of acquired etiologies for PAA, including infections with tuberculosis, syphilis or other bacterial endocarditis, and septic embolisms. ${ }^{7-9}$ Furthermore , a number of autoimmune and connective tissue disorders have been implicated in causing PAA. ${ }^{10,11}$ Greene et al., suggested 4 pathological and clinical criteria for an idiopathic PAA: i) simple dilatation of the pulmonary trunk with or without involvement of the rest of the arterial tree, ii) absence of intracardiac or extracardiac shunts, iii) absence of chronic cardiac or pulmonary disease, and iv) absence of arterial disease such as syphilis or arteriosclerosis of the pulmonary vascular tree. ${ }^{12}$ Pulmonary hypertension is an important causative and prognostic factor for PAA and plays a critical role in treatment decision.

In this issue of the Journal of Cardiac Surgery, Pelenghi et al., reported a successful operation that includes bilateral lung transplant, pulmonary artery aneurysmorrhaphy and pulmonary valve replacement in a patient with severe idiopathic pulmonary arterial hypertension complicated by giant pulmonary aneurysm, pulmonary valve regurgitation and right ventricle dysfunction. ${ }^{13}$ The patient was initially listed for heartlung transplantation, but because of the unavailability of a heart-lung donor and clinical deterioration after 7 months on the waiting list, the patient's listing status was converted to bilateral lung transplant. She underwent bilateral lung transplant (BLT), PA aneurysmorrhaphy and open deployment of an injectable porcine pulmonic valve (No-React @ Injectable BioPulmonic valves, Bio Integral Surgical, Inc., Mississauga, ON, Canada) that was designed for percutaneous deployment. Bilateral sequential lung transplant or enbloc double lung transplant, along with repair or replacement of pulmonary artery and valve for patients with PAA and severe pulmonary hypertension, have been previously reported. ${ }^{14-16}$ However, this is the first reported case of using such a bioprosthesis in this clinical scenario. The long-term outcome of this device, which is prone to early failure ( $85 \%$ failure rate at 5.2 years), is uncertain. ${ }^{17}$

Currently, there is no clear guideline for treating patients with PAA because the rarity of the disease, and the paucity of data on its natural history and long-term outcomes. Treatment options include close observation, medical treatment, repair of the aneurysm, and in cases associated with severe pulmonary hypertension, bilateral lung or combined heart-lung transplantation. For patients with a low-pressure PAA without left-to-right shunting, a more cautious approach may be warranted. ${ }^{18,19}$ In these patients, some authors recommended that the timing of surgical intervention is dictated by changing of ventricular size and function, and clinical symptoms, but not so much on the size of the aneurysm because the incidence of rupture is low. ${ }^{18,19}$ However, Kreibich et al., recommended surgical repair in adults with pulmonary trunk aneurysms $>5.5 \mathrm{~cm}$, similar to the guidelines for aortic disease. ${ }^{3}$

If the signs of right ventricular dysfunction, or pulmonary valve dysfunction start to appear, early surgical repair is recommended. In low pressure isolated PAA, several surgical procedures have been reported. Pulmonary aneurysmorrhaphy is a relatively simple and not time-consuming however, this procedure will result in high recurrent rate, especially in PAA related to connective tissue disorders or congenital structural heart diseases. Therefore, aneurysmectomy and replacing the pulmonary artery with a vascular conduit is advised. ${ }^{20}$ Various types of conduits have been described, including polytetrafluoroethylene or dacron vascular grafts, aortic or pulmonary homografts, porcine aortic xenografts, and bovine jugular vein graft. ${ }^{21,22}$

A more aggressive surgical approach has been advocated for patients with PAA and pulmonary arterial hypertension because of the risk of dissection and rupture. ${ }^{23,24}$ In cases of pulmonary hypertension with 
preserved right and left ventricle function, bilateral lung transplant is the preferred option, and the donor main PA can be used to replace the recipient's PA and pulmonary trunk. ${ }^{14}$ If the donor PA is short, pulmonary trunk of the recipient can be reconstructed with the donor's aortic arch. ${ }^{15}$

Many patients with PAA also present with pulmonary valve regurgitation (PVR), resulting from annular dilatation due to the PAA or from other independent etiologies. ${ }^{25,26}$ When the pulmonary valve (PV) is competent, a valve-sparing technique should be performed, whereas the valve is repaired or replaced if there is significant deformity and regurgitation. ${ }^{27}$ In the case reported in the current issue of the journal, Pelenghi et al., elected to replace the PV by open deployment of an injectable porcine pulmonic valve (No-React(r) Injectable BioPulmonic valves) that was designed for percutaneous deployment. ${ }^{13}$ The problem with this valve is that it has very poor long-term outcome when deployed percutaneously in pediatric patients due to either malposition or neointimal proliferation. ${ }^{17}$ It remains to be seen how this valve performs in an adult patient on immunosuppression.

In years past heart-lung transplant (HLT) was the treatment of choice for patients with severe pulmonary hypertension. The first successful heart-lung transplant was performed on a patient with idiopathic pulmonary hypertension on March 9, 1981. ${ }^{28}$ As the lung transplantation field matures and because of the severe shortage of heart-lung donors, bilateral lung transplant has replaced heart-lung transplant as the primary treatment option for patients with pulmonary hypertension and preserved right and left ventricular function. $^{29}$

In patients with high pressure PAA with poor RV or LV function or due to complicated cardiac congenital abnormalities (Eisenmenger Syndrome; ES), combined heart-lung transplantation is indicated. For patients with ES, the choice between bilateral lung transplant and heart-lung transplant depends on the anomalies and whether the lesion is surgically correctable. Using the United Network for Organ Sharing (UNOS) database Federico et al., analyzed the outcomes of patients with ES who underwent thoracic transplantation from 1987 to $2018 .{ }^{16}$ During the study period, 442 adults with ES underwent either bilateral lung transplant $(\mathrm{n}=126)$ or heart lung transplant $(\mathrm{n}=316)$. The long-term survival was comparable between the two groups. However, subgroup analyses showed that patients with atrial septal defect (ASD) fared better with BLT while those with ventricular septal defect (VSD) had better survival following HLT.

In conclusion, the treatment of severe pulmonary arterial hypertension has evolved over the last four decades to allow for more expanded selection criteria in the recipients, and utilization of different ingenious modifications to deal with abnormalities of the pulmonary artery and valve. It has been well documented that, in appropriately selected patients, bilateral lung transplant is the treatment of choice for those with severe pulmonary hypertension. The question that remains is what to do with the pulmonary arterial aneurysm and pulmonary valve regurgitation. Should the aneurysm be repaired with aneurysmorraphy and risk high recurrence or should it be replaced, and if replaced, with what material? Similarly, should a morphologically normal valve that has regurgitation because of annular dilatation be repaired or replaced, and if replaced, with what valve type? The case described in this issue of the journal by Pelenghi et al., and other published reports do not provide us with satisfactory answers, and we may not have these answers any time soon because of the rarity of the condition. But we are confident that as more cases are studied and followed longitudinally, we will be able to provide better recommendations for our patients. The first successful heartlung transplant as a treatment pulmonary hypertension was a true "paradigm shift", or a "revolution". From this "revolution" the surgical treatment for patients with severe pulmonary hypertension, with or without PAA, has evolved to include either bilateral lung or heart-lung transplantation as the appropriate treatment for each individual patient.

Author contributions Concept/design: SJ, BS, SMP. Drafting article: SJ; Critical revision of article: ANP, BS, SMP; Approval of article: SJ, ANP, BS, SMP.

\section{References:}

1. Deterling RA, Clagett OT. Aneurysm of the pulmonary artery: Review of the literature and report of a case. American Heart Journal.1947;34(4):471-499. 
2. Hou R, Ma GT, Liu XR, et al. Surgical treatment of pulmonary artery aneurysm: an institutional experience and literature review.Interact Cardiovasc Thorac Surg. 2016;23(3):438-442.

3. Kreibich M, Siepe M, Kroll J, Hohn R, Grohmann J, Beyersdorf F. Aneurysms of the pulmonary artery. Circulation.2015;131(3):310-316.

4. Brown JR, Plotnick G. Pulmonary artery aneurysm as a cause for chest pain in a patient with Noonan's syndrome: a case report. Cardiology. 2008;110(4):249-251.

5. Blades B, Ford W, Clark P. Pulmonary Artery Aneurysms. Circulation. 1950;2(4):565-571.

6. Bartter T, Irwin RS, Nash G. Aneurysms of the pulmonary arteries. Chest. 1988;94(5):1065-1075.

7. Warthin A. Syphilis of the pulmonary artery: syphilitic aneurysm of the left upper division: demonstration of spirochete pallida in wall of artery and aneurysmal sac. Am J Syph. 1917;1(4):693-711.

8. Plessinger VA, Jolly PN. Rasmussen's aneurysms and fatal hemorrhage in pulmonary tuberculosis. Am Rev Tuberc. 1949;60(5):589-603, illust.

9. Kim HS, Oh YW, Noh HJ, Lee KY, Kang EY, Lee SY. Mycotic pulmonary artery aneurysm as an unusual complication of thoracic actinomycosis.Korean J Radiol. 2004;5(1):68-71.

10. Kohno S, Fujikawa M, Kanda T, Asai S, Hirota M, Sameshima Y. A case of Behcet's syndrome with rupture of a pulmonary aneurysm: autopsy findings and a literature review. Jpn J Med. 1986;25(3):293-300.

11. Chalazonitis AN, Lachanis SB, Mitseas P, et al. Hughes-Stovin syndrome: a case report and review of the literature. Cases J.2009;2:98.

12. Greene DG, Baldwin ED, et al. Pure congenital pulmonary stenosis and idiopathic congenital dilatation of the pulmonary artery. Am J Med. 1949;6(1):24-40.

13. Pelenghi S, Primiceri C, Belliato M, Ghio S, Scelsi L, Totaro P. Is it time for a paradigm shift: Should double-lung transplant be considered the treatment of choice for Idiopathic pulmonary arterial hypertension and giant pulmonary aneurysm. J Card Surg. (in press).

14. Shayan H, Sareyyupoglu B, Shigemura N, Thacker J, Bermudez C, Toyoda Y. Lung transplant, double valve repair, and pulmonary artery aneurysm resection. Ann Thorac Surg. 2012;93(1):e3-5.

15. Force SD, Lau CL, Moazami N, Trulock EP, Patterson GA. Bilateral lung transplantation and pulmonary artery reconstruction in a patient with chronic obstructive pulmonary disease and a giant pulmonary artery aneurysm. J Thorac Cardiovasc Surg. 2003;126(3):864-866.

16. Sertic F, Han J, Diagne D, et al. Not All Septal Defects Are Equal: Outcomes of Bilateral Lung Transplant With Cardiac Defect Repair vs Combined Heart-Lung Transplant in Patients With Eisenmenger Syndrome in the United States. Chest. 2020;158(5):2097-2106.

17. Grohmann J, Hohn R, Fleck T, et al. No-React(r) Injectable BioPulmonic valves re-evaluated: discouraging follow-up results.Interact Cardiovasc Thorac Surg. 2015;21(5):657-665.

18. Veldtman GR, Dearani JA, Warnes CA. Low pressure giant pulmonary artery aneurysms in the adult: natural history and management strategies. Heart. 2003;89(9):1067-1070.

19. Casselman F, Meyns B, Herygers P, Verougstraete L, Van Elst F, Daenen W. Pulmonary artery aneurysm: is surgery always indicated? Acta Cardiol. 1997;52(5):431-436.

20. Kuwaki K, Morishita K, Sato H, Urita R, Abe T. Surgical repair of the pulmonary trunk aneurysm. Eur J Cardiothorac Surg.2000;18(5):535-539.

21. Herijgers P, Ozaki S, Verbeken E, et al. Valved jugular vein segments for right ventricular outflow tract reconstruction in young sheep. J Thorac Cardiovasc Surg. 2002;124(4):798-805. 
22. Boethig D, Thies WR, Hecker H, Breymann T. Mid term course after pediatric right ventricular outflow tract reconstruction: a comparison of homografts, porcine xenografts and Contegras. Eur $J$ Cardiothorac Surg. 2005;27(1):58-66.

23. Axmann C, Theuerkauf I, Flacke S. [Delineated aneurysms of the large pulmonary arteries. A rare sequela of pulmonary hypertension].Rofo. 2002;174(11):1460-1461.

24. Smalcelj A, Brida V, Samarzija M, Matana A, Margetic E, Drinkovic N. Giant, dissecting, high-pressure pulmonary artery aneurysm: case report of a 1-year natural course. Tex Heart Inst J. 2005;32(4):589-594.

25. Metras D, Ouattara K, Quezzin-Coulibaly A. Aneurysm of the pulmonary artery with cystic medial necrosis and massive pulmonary valvular insufficiency. Report of two successful surgical cases. Eur $J$ Cardiothorac Surg. 1987;1(2):119-124.

26. Iosifescu AG, Dorobantu LF, Anca TM, Iliescu VA. Surgical treatment of a pulmonary artery aneurysm due to a regurgitant quadricuspid pulmonary valve. Interact Cardiovasc Thorac Surg.2012;14(6):880-882.

27. Muthialu N, Raju V, Muthubaskaran V, Chandrasekar P, Muralidharan S, Kuppanna PJ. Idiopathic pulmonary artery aneurysm with pulmonary regurgitation. Ann Thorac Surg. 2010;90(6):2049-2051.

28. Reitz BA, Wallwork JL, Hunt SA, et al. Heart-lung transplantation: successful therapy for patients with pulmonary vascular disease. N Engl J Med. 1982;306(10):557-564.

29. Bolman RM, 3rd, Shumway SJ, Estrin JA, Hertz MI. Lung and heart-lung transplantation. Evolution and new applications. Ann Surg.1991;214(4):456-468; discussion 469-470. 